\title{
Probiotic Viability, Qualitative Characteristics, and Sensory Acceptability of Vegetable Juice Mixture Fermented with Lactobacillus Strains
}

\author{
Thi Van Thanh Do, Liuping Fan* \\ National Engineering Research Center for Functional Food, School of Food Science and Technology, Jiangnan University, Wuxi, \\ China \\ Email: ^fanliuping@jiangnan.edu.cn
}

How to cite this paper: Do, T.V.T. and Fan, L.P. (2019) Probiotic Viability, Qualitative Characteristics, and Sensory Acceptability of Vegetable Juice Mixture Fermented with Lactobacillus Strains. Food and Nutrition Sciences, 10, 412-427.

https://doi.org/10.4236/fns.2019.104031

Received: March 14, 2019

Accepted: April 15, 2019

Published: April 19, 2019

\section{Copyright $\odot 2019$ by author(s) and} Scientific Research Publishing Inc. This work is licensed under the Creative Commons Attribution International License (CC BY 4.0).

http://creativecommons.org/licenses/by/4.0/

\begin{abstract}
The aim of the study was to consider the suitability of a mixture of juices from jicama, winter melon, and carrot as a raw medium for producing probiotic juice by Lactobacillus strains (Lactobacillus plantarum CICC22696 and Lactobacillus acidophilus CICC20710), as well as evaluate changes of physicochemical and microbiological characteristics during fermentation and cold storage $\left(4^{\circ} \mathrm{C}, 28\right.$ days). Both strains grew well in juice mixtures after $24 \mathrm{~h}$ of fermentation at $37^{\circ} \mathrm{C}$, reaching nearly 9 and $8 \log \mathrm{CFU} / \mathrm{mL}$ when inoculated with $L$. plantarum and $L$. acidophilus respectively. The viability of $L$. plantarum was near $8 \log \mathrm{CFU} / \mathrm{mL}$ at the end of storage whereas viability of $L$. acidophilus only remained $4.57 \log \mathrm{CFU} / \mathrm{mL}$. Degradation of total carotenoids was in the range of $12 \%-23 \%$ in fermentation periods and $16 \%-23 \%$ during cold storage depending on the strain used. The values of lightness, redness, and yellowness increased during fermentation. However, this tendency was variable during cold storage when the values of redness and yellowness decreased. Sensory acceptability of the products was enhanced by adding sucrose or multi fruit juice (containing mainly tropical fruit juices). The fermented juice with $L$. plantarum is efficient to produce a functional probiotic beverage.
\end{abstract}

\section{Keywords}

Vegetable Juice Mixture, Lactobacillus Strains, Fermentation, Probiotic Drink, Acceptability

\section{Introduction}

Probiotics are defined as live organisms, which provide a benefit to the host 
when administered in adequate quantities [1]. Fermented products as a component of a daily diet, may improve the health and life quality of consumers. Beneficial effects of probiotic bacteria in food include reduction in the level of serum cholesterol, improvement in lactose metabolism, enhanced immune system, lower risk of colon cancer, control of gastrointestinal infections, improved antimutagenic properties, and stimulation of anti-diarrheal properties [2] [3]. The genera Lactobacillus and Bifidobacterium are the most common probiotic microorganisms used commercially in the food industry which comprise more than $90 \%$ of probiotic food supplements. Probiotics have been regularly incorporated in yogurt or other fermented dairy products, however, cannot be consumed by humans who are suffering from lactose intolerance and/or allergic to milk proteins. Moreover, consumers tend to prefer the food and beverages that are fresh, highly nutritional, health promoting and ready to consume. Some matrices have been used in the development of non-dairy probiotic products such as fruits, vegetables, legumes, and cereals [4].

Through fermentation, fruit and vegetable juices are preserved and maintained, while improving the nutritive and sensory properties of the products. Various studies have been conducted to investigate the suitability of fruit and vegetable juices as a medium to develop new probiotic beverages from fruits such as pineapple [5], pear [6], grape [7], pomegranate [8] guava [3], fig [2], noni [9], both barberry and black cherry [10] and vegetables such as carrot [11], beet [12], sweet potato [13], potato [14]. However, the survival of probiotics in fruit and vegetable-based matrices is more complex than in dairy products. Probiotic bacteria need protection from the acidic conditions in these media. Moreover, probiotic stability in fruit and vegetable juice products is difficult to maintain during cold storage [15].

Vegetables are rich sources of bioactive compounds which have beneficial effects in prevention of some diseases and certain types of cancer [12]. Jicama (Pachyrhizus erosus), also called yam bean, is an edible tuberous root placed in the spotlight as a healthy food ingredient. It is rich in vitamin C, fructooligosaccharides (FOSs), and inulin, a soluble fiber can serve as a potential prebiotic, and appreciable levels of nutraceuticals [16] [17]. Jicama also has other biological benefits such as immunomodulatory activity [18], reducing the risk of colon cancer [19], and anti-diabetic properties [20]. Winter melon (Benincasa hispida (Thunb.) Cogn), a widely used vegetable in India, China and other tropical countries, belongs to the Cucurbitaceous fruit family [21]. It contains carbohydrates, with $8 \mathrm{~g}$ carbohydrates and $1.5 \mathrm{~g}$ protein in every $0.5 \mathrm{~kg}$ of winter melon [22]. Winter melon has been evaluated to be a potential source of antioxidants for functional drinks and nutraceutical application and has good angiotension-converting enzyme inhibition capacity, which may offer protective effects against cardiovascular diseases, diabetic complications and certain types of cancers [23]. Moreover, benefits of winter melon are used to treat hydrops and turgor, beriberi, stranguria, cough, asthma with rale, fidgets due to summer-heat, diabetes, diarrhea, dysentery, carbuncle, and swelling [24]. Therefore, winter 
melon and jicama are ideal substrates to combine with carrots (Daucus carota $\mathrm{L}$.), which are rich in carbohydrates, $\beta$-carotene, vitamins (A, D, B, E, C, and $\mathrm{K}$ ), and minerals for the growth of beneficial lactic acid bacteria in the beverages.

To our knowledge, studies dealing with the fermented drink/juice made from jicama and/or winter melon have not been explored. Most fermented juices from fruits and vegetables in past studies used lactic acid bacteria, researchers just limited investigation scope at considering the suitability for producing probiotic juice. Therefore, this study had three main objectives:

1) To investigate the suitability of a vegetable juice medium composed of jicama, winter melon and carrot juices as raw material for production of probiotic vegetable juice by lactic acid bacteria.

2) To determine physicochemical and microbiological changes during fermentation and cold storage of the vegetable juice mixture.

3) To evaluate sensory acceptability of products, furthermore, to confirm whether the addition of sucrose or multi fruit juice (mainly tropical fruit juices) improves sensory quality and hedonics.

\section{Materials and Methods}

\subsection{Preparation of Vegetable Juice Mixture}

Jicamas, winter melon with sparser wax covering its surface, and orange carrots were purchased from the supermarket Auchan and local market in Binhu district, kept at $4^{\circ} \mathrm{C}$, and used in the experiment as quickly as possible. Vegetables were careful washed and peeled. The seeds and cavity tissues were removed from the winter melon. Juices were extracted from jicama, winter melon and carrots using a Philips Viva Collection juicer (Shengzheng, China). The extracted juices were filtered separately through a cheesecloth. The clarified juices from jicama, winter melon, carrots were combined in a ratio of 1:1:1 by volume. The juice mixture was analyzed yielding the following characteristics: titratable acidity of $0.09 \%$ (expressed as lactic acid), $\mathrm{pH}$ of 6.05 and total soluble solid content of $6.0^{\circ}$ Brix. The fresh juice mixture was subjected to pasteurization in a TOMY SX-500-high pressure steam sterilizer (Tomy Kogyo Co. Ltd, Fukushima, Japan) at $80^{\circ} \mathrm{C}$ for $15 \mathrm{~min}$ [25] in $250 \mathrm{ml}$ Erlenmeyer flasks, then cooled immediately by letting it sit at ice bath to $25^{\circ} \mathrm{C}$. Each of the sealed Erlenmeyer flasks contained $100 \mathrm{~mL}$ pasteurized juice mixture without any nutrient supplements or water. The pasteurized vegetable juice mixture was designated as the control formulation (CON).

\subsection{Strains and Microbial Culture Stock Preparation}

Lactic acid bacteria (L. plantarum CICC 22696, L. acidophilus CICC 20710) were supplied by China Center of Industrial Culture Collection (CICC), Beijing, China. Both bacterial cultures were stored frozen at $-20^{\circ} \mathrm{C}$ in MRS (De Man, Rogosa and Sharpe) medium containing $20 \%$ glycerol. The strains were reactivated by means of double passage on MRS when needed according to the instructions in the user's manual. 


\subsection{Fermentation of Vegetable Juice Mixture}

Lactobacillus strains were cultivated on MRS broth at $37^{\circ} \mathrm{C}$. When used for fermentation, lactic acid bacteria were cultivated until the late exponential phase of growth was reached. The exponential phase was determined from bacterial growth curve. Erlenmeyer flasks containing $100 \mathrm{~mL}$ of pasteurized juice mixture were then inoculated the culture to nearly $7.00 \log \mathrm{CFU} / \mathrm{mL}$, this concentration was chosen based on the recommendation for probiotic foods: minimal counts of $7.00 \log \mathrm{CFU} / \mathrm{mL}$ for better efficacy in regulating beneficial effects [26]. For obtaining an initial cell density of $7.00 \log \mathrm{CFU} / \mathrm{mL}$ in the final juice, $1.8 \mathrm{~mL}$ of cultivated MRS broth of $L$. plantarum and $5 \mathrm{~mL}$ of cultivated MRS broth of $L$. acidophilus were centrifuged at $3000 \mathrm{~g}$ for $5 \mathrm{~min}$. The biomass of the strain was introduced into the juice $(100 \mathrm{ml})$. Fermentations were carried out in an incubator for juices inoculated with $L$. plantarum and in an anaerobic incubator for juices inoculated with $L$. acidophilus at a constant temperature of $37^{\circ} \mathrm{C}$ for $48 \mathrm{~h}$. Samples were taken at $0,24,48 \mathrm{~h}$ for physiochemical and microbiological analysis.

\subsection{Effects of Cold Storage on Fermented Vegetable Juice Mixture}

To determine the effects of cold storage on cell viability and physicochemical properties after completion of appropriate fermentation time, samples of fermented juice mixture were transfer to storage at $4^{\circ} \mathrm{C}$ for 28 days. Viable counts, color and total carotenoids of fermented vegetable juice were recorded at intervals of 7 days, during the 28 days. The microbial population was expressed as log $\mathrm{CFU} / \mathrm{mL}$.

\subsection{Chemical and Microbiological Analysis}

\subsubsection{Determination of $\mathrm{pH}$ and Total Soluble Solid (TSS) Content}

A digital F2-standard pH meter (Mettler-Toledo Instruments (Shanghai) Ltd, China) was used for $\mathrm{pH}$ measurements. The total soluble solid ( ${ }^{\circ} \mathrm{Brix}$ ) of the juice was measured using a refractometer (Master-20M, ATAGO Co., Ltd., Tokyo, Japan).

\subsubsection{Determination of Titratable Acidity and Total Sugar}

Total acidity expressed as percent of lactic acid, was determined by titrating the juice sample $(10 \mathrm{~mL})$ with $0.1 \mathrm{~N} \mathrm{NaOH}$ to the end point ( $\mathrm{pH} 8.2 \pm 0.1)$ [27]. The total sugar content was analyzed as glucose using the phenol sulfuric acid method of Dubois, Gilles [28].

\subsubsection{Determination of Total Carotenoid Content}

The total carotenoid content of the sample was determined by a slightly modified method of Adiamo, Ghafoor [29]. $5 \mathrm{~mL}$ of vegetable juice mixture was added to $50 \mathrm{~mL}$ of extraction solvent (petroleum ether: methanol 90: 10) in a separatory funnel. The mixture was vigorously mixed by hand and then stood for 5 min to separate solvent phase. The extraction process was repeated with $50 \mathrm{~mL}$ 
fresh extraction solvent. The aqueous phase was discarded. The solvents were collected together and centrifuged at $900 \mathrm{~g}$ for $15 \mathrm{~min}$. The absorbance of supernatant was read immediately at $450 \mathrm{~nm}$ using a L8 UV-vis spectrophotometer (INESA, China). The concentration of carotenoids was expressed as $\beta$-carotene $(\mathrm{mg} / \mathrm{L})$. The total carotenoid content was calculated using the following formula:

$$
\text { Carotenoids content }(\mathrm{mg} / \mathrm{L})=\frac{A \times V(\mathrm{~mL}) \times 10^{4}}{E_{1 \mathrm{~cm}}^{1 \%} \times P}
$$

where $A=$ absorbance; $V=$ total extract volume; $P=$ analyzed juice volume $(\mathrm{mL}) ; E_{1 \mathrm{~cm}}^{1 \%}=2592$ ( $\beta$-carotene extinction coefficient in petroleum ether).

\subsubsection{Viable Cell Counts}

Viable cell counts were obtained by serial dilution with saline until $10^{7}$ dilution was reached. Aliquots of $0.1 \mathrm{ml}$ of dilution were plated in triplicate on petri-dishes containing MRS agar. The petri-dishes were incubated for $48 \mathrm{~h}$ ( $L$. plantarum CICC22696) and for $72 \mathrm{~h}$ (L. acidophilus CICC20710) at $37^{\circ} \mathrm{C}$. Plates containing 20 - 350 colonies were measured and recorded as colony forming units $(\log \mathrm{CFU} / \mathrm{mL})$. L. acidophilus appears on agar as irregular light brown colonies ranging in diameter from 0.9 to $1.5 \mathrm{~mm}$ [30]. L. plantarum characterizes small circular, rough, dull white and convex colonies [31].

\subsection{Color Analysis}

The juice color was determined by using an UltraScan Pro1166 spectrophotometer (Hunterlab, America), and readings were taken in triplicate. The reflectance instruments determined three color parameters: lightness $\left(L^{\star}\right)$, redness $\left(\mathrm{a}^{*}\right)$, and yellowness $\left(\mathrm{b}^{\star}\right)$. The index of total color difference $(\Delta \mathrm{E})$ was calculated by the equation $\left[\left(L-L_{\mathrm{o}}\right)^{2}+\left(a-a_{o}\right)^{2}+\left(b-b_{o}\right)^{2}\right]^{1 / 2}$. Where $L_{o}, a_{0}$, and $b_{o}$ are referred to the color reading of control sample. A larger $\Delta \mathrm{E}$ value indicates the greater color change compared with the control sample.

\subsection{Sensory Evaluation}

Seven formulations of vegetable juice mixture were prepared for assessment shown as Table 1. On day 14 of product storage, three versions of the fermented vegetable juice mixtures were served to judges: juice mixture without any supplements (PFJ and AFJ), juice mixture with added with sucrose to $10^{\circ}$ Brix (SUC-PFJ and SUC-AFJ), or multi fruit juice (10\% v/v; MASK-PFJ and MASK-AFJ). The commercial multi fruit juice (Farmerland; e.g., containing orange, grape, mango, tangerine, peach, pineapple, grapefruit, apple, kiwi, and passion fruit juices) of manufacturer (Rea Coop 21200, Argos-Greece) was used for addition based on report of Luckow, Sheehan [32]. The authors emphasized that the tropical fruit juice could positively mask the off-flavors in probiotic juice and contribute to the aroma and flavor of the final product.

The sensory characteristics were evaluated by a panel of 21 judges involved students in faculty of food science and technology who were not familiar with 
Table 1. Experimental design of vegetable juice mixture formulations.

\begin{tabular}{cccc}
\hline Formulations & $\begin{array}{c}\text { Fermented juice by Lactoba- } \\
\text { cillus strain }\end{array}$ & Sucrose & Multi fruit juice \\
\hline CON & - & - & - \\
PFJ & L. plantarum & - & - \\
AFJ & L. acidophilus & - & - \\
SUC-PFJ & L. plantarum & Added to $10^{\circ} \mathrm{Brix}$ & - \\
SUC-AFJ & L. acidophilus & Added to $10^{\circ} \mathrm{Brix}$ & - \\
MASK-PFJ & L. plantarum & - & $10 \% \mathrm{v} / \mathrm{v}$ \\
MASK-AFJ & L. acidophilus & - & $10 \% \mathrm{v} / \mathrm{v}$
\end{tabular}

characteristics of fermented non-dairy beverage. The judges (13 women, 8 men) ranged from 24 - 35 years old. Two evaluation sessions were conducted in individual booths. All samples of $40 \mathrm{ml}$ were coded with 3-digit random numbers, presented to the panelists at room temperature and evaluated one at a time, in random order. Room temperature spring water was provided to panel members for rinsing the mouth between samples. The acceptance testing of attributes (color, texture, flavor, taste and overall acceptance) used a 9-point hedonic scale, ranging from 1 to 9 where $9=$ like extremely and $1=$ dislike extremely. The evaluation data were recorded and mean scores for each attribute were calculated to compare with the samples.

\subsection{Statistical Analysis}

All experimental results were the mean of triplicate. The data were recorded as the mean \pm standard deviation (mean $\pm \mathrm{SD}$ ) and the statistical analysis was conducted with IBM SPSS software (version 24, Statsoft, America). Data analysis was done by one-way ANOVA followed by Duncan's post hoc test. Results were regarded as significant differences at $\mathrm{p}<0.05$.

\section{Results and Discussion}

\subsection{Fermentation Characteristics}

\subsubsection{Growth and Productivity of Lactobacteria}

Table 2 and Table 3 present the time courses of lactic acid fermentation of vegetable juice mixture by $L$. plantarum and L. acidophilus, respectively. Both Lactobacillus strains were found to be capable of rapid growth in the vegetable juice mixture medium with lactic acid production without any nutrient supplementation or altering of the structural characteristics of source matrices. The similarity of $\mathrm{pH}$ between the pre-culture of MRS broth $(\mathrm{pH}=6.8)$ and the initial vegetable juice mixture ( $\mathrm{pH}$ of about 6.0) resulted in the rapid growth rate of Lactobacillus strains. Moreover, inulin and FOSs in the juice mixture could be helpful to improve the growth and increase counts of the strains [33]. L. plantarum had a greater growth than $L$. acidophilus in the juice. The bacterial population of L. plantarum and L. acidophilus respectively reached nearly 9 and $8 \log$ 
Table 2. Time course of lactic fermentation of vegetable juice mixture by L. plantarum.

\begin{tabular}{ccccccc}
\hline $\begin{array}{c}\text { Time } \\
(\mathrm{h})\end{array}$ & $\mathrm{pH}$ & TTS ( Brix) & $\begin{array}{c}\text { Titratable acidity } \\
\text { (\%lactic acid) }\end{array}$ & Log CFU/mL & $\begin{array}{c}\text { Total sugar } \\
(\mathrm{mg} / \mathrm{mL})\end{array}$ & $\begin{array}{c}\text { Total } \\
\text { carotenoids } \\
(\mathrm{mg} / \mathrm{L})\end{array}$ \\
\hline $0 \mathrm{~h}$ & $5.97 \pm 0.01^{\mathrm{a}}$ & $6.4 \pm 0.06^{\mathrm{a}}$ & $0.09 \pm 0.01^{\mathrm{c}}$ & $6.80 \pm 0.09^{\mathrm{c}}$ & $48.76 \pm 0.71^{\mathrm{a}}$ & $24.22 \pm 0.13^{\mathrm{a}}$ \\
$24 \mathrm{~h}$ & $3.68 \pm 0.01^{\mathrm{b}}$ & $5.3 \pm 0.06^{\mathrm{b}}$ & $0.61 \pm 0.01^{\mathrm{b}}$ & $8.98 \pm 0.04^{\mathrm{a}}$ & $37.02 \pm 1.01^{\mathrm{b}}$ & $21.32 \pm 0.29^{\mathrm{b}}$ \\
$48 \mathrm{~h}$ & $3.40 \pm 0.01^{\mathrm{c}}$ & $5.0 \pm 0.00^{\mathrm{c}}$ & $0.95 \pm 0.05^{\mathrm{a}}$ & $8.77 \pm 0.11^{\mathrm{b}}$ & $34.66 \pm 1.04^{\mathrm{c}}$ & $19.54 \pm 0.14^{\mathrm{c}}$ \\
\hline
\end{tabular}

Data expressed as means \pm standard deviation $(n=3)$. Values in the same column followed by different superscript letters indicate statistically significant differences at $\mathrm{p}<0.05$. TSS: total soluble solid.

Table 3. Time course of lactic fermentation of vegetable juice mixture by L.acidophilus.

\begin{tabular}{ccccccc}
\hline $\begin{array}{c}\text { Time } \\
(\mathrm{h})\end{array}$ & $\mathrm{pH}$ & TTS ( Brix) & $\begin{array}{c}\text { Titratable acidity } \\
\text { (\%lactic acid) }\end{array}$ & Log CFU/mL & $\begin{array}{c}\text { Total sugar } \\
(\mathrm{mg} / \mathrm{mL})\end{array}$ & $\begin{array}{c}\text { Total carote- } \\
\text { noids (mg/L) }\end{array}$ \\
\hline $0 \mathrm{~h}$ & $5.98 \pm 0.04^{\mathrm{a}}$ & $6.4 \pm 0.10^{\mathrm{a}}$ & $0.09 \pm 0.01^{\mathrm{c}}$ & $6.59 \pm 0.05^{\mathrm{c}}$ & $47.93 \pm 1.07^{\mathrm{a}}$ & $23.63 \pm 0.22^{\mathrm{a}}$ \\
$24 \mathrm{~h}$ & $3.96 \pm 0.01^{\mathrm{b}}$ & $5.6 \pm 0.06^{\mathrm{b}}$ & $0.49 \pm 0.02^{\mathrm{b}}$ & $7.89 \pm 0.01^{\mathrm{a}}$ & $40.27 \pm 0.89^{\mathrm{b}}$ & $20.19 \pm 0.24^{\mathrm{b}}$ \\
$48 \mathrm{~h}$ & $3.83 \pm 0.01^{\mathrm{c}}$ & $5.4 \pm 0.00^{\mathrm{c}}$ & $0.59 \pm 0.01^{\mathrm{a}}$ & $7.42 \pm 0.03^{\mathrm{b}}$ & $38.67 \pm 0.77^{\mathrm{b}}$ & $18.25 \pm 0.38^{\mathrm{c}}$
\end{tabular}

Data expressed as means \pm standard deviation $(n=3)$. Values in the same column followed by different superscript letters indicate statistically significant differences at $\mathrm{p}<0.05$. TSS: total soluble solid.

$\mathrm{CFU} / \mathrm{mL}$ after $24 \mathrm{~h}$ then slightly decreased to 8.77 and $7.42 \log \mathrm{CFU} / \mathrm{mL}$ after $48 \mathrm{~h}$ of fermentation at $37^{\circ} \mathrm{C}$. Extending the growth period to $48 \mathrm{~h}$ did not increase the number of viable cells of any tested starter but did reduce cell viability. For maximum health benefits, scientists have suggested the minimum probiotic organism level in probiotic food products should be $10^{6}-10^{7} \mathrm{CFU} / \mathrm{mL}$ at the time of consumption [34]. Therefore, to be effective in producing a probiotic beverage, the fermentation time of $24 \mathrm{~h}$ was chosen as a proper fermentation period to consider the effect of cold storage on fermented vegetable juice mixture. The initial population of lactic acid bacteria before cold storage at $4^{\circ} \mathrm{C}$ could affect the final survival of bacteria [35].

\subsubsection{Change of pH, TTS, and Titratable Acidity during Fermentation}

The $\mathrm{pH}$ and TSS of vegetable juice decreased during the fermentation process (Table 2 and Table 3). For example, L. plantarum and L. acidophilus reduced the $\mathrm{pH}$ from an initial value of 5.97 and 5.98 to 3.40 and 3.83 and the TSS from an initial value of 6.4 to 5.0 and 5.4 after $48 \mathrm{~h}$ of fermentation, respectively. The decrease in $\mathrm{pH}$ during lactic acid fermentation was due to accumulation of organic acids especially lactic acid. Under the same growth conditions, $L$. plantarum showed a more rapid drop in $\mathrm{pH}$ and TSS and produced significantly more lactic acid than $L$. acidophilus. It could be due to the requirement of $L$. acidophilus for essential growth nutrients that are deficient in the vegetable juice mixture. The obtained result agreed with the findings by researchers in tomato, cabbage, and vegetable juice fermented with lactic acid bacteria [36] [37] [38].

\subsubsection{Change of Total Sugar and Total Carotenoid Content}

The strains rapidly fermented the vegetable juice mixture and resulted the re- 
duction of total sugar and carotenoids. The greater growth and metabolism of $L$. plantarum have led to higher sugar consumption than L. acidophilus, and decreased the initial sugar content of $48.76 \mathrm{mg} / \mathrm{mL}$ to $34.66 \mathrm{mg} / \mathrm{mL}$. There was about $29.70 \mathrm{mg}$ of carotenoids in $1 \mathrm{~L}$ of fresh vegetable juice mixture extracted with the Philips Viva Collection juicer. Pasteurizing $\left(80^{\circ} \mathrm{C}, 15 \mathrm{~min}\right)$ substantially reduced total carotenoid content in fresh juice mixture to $\sim 23-24 \mathrm{mg} / \mathrm{L}$ (Table 2 and Table 3). This amount decreased after $48 \mathrm{~h}$ of fermentation with both strains. When inoculated with $L$. plantarum, about $12 \%$ and $19 \%$ of carotenoid content were lost after $24 \mathrm{~h}$ and $48 \mathrm{~h}$ of fermentation, respectively. When inoculated with $L$. acidophilus the reductions were greater, with $15 \%$ and $23 \%$ lost after $24 \mathrm{~h}$ and $48 \mathrm{~h}$ of fermentation, respectively. Carotenoid degradation could be due to the metabolism of bacteria and fermentation conditions (temperature, $\mathrm{pH}$, time). The level of effect depends on the strain used, substrate, and factors of fermentation [13] [25] [39].

\subsubsection{Effect of Fermentation on Color Change}

Table 4 presents the results regarding effect of fermentation on color components $\left(L^{\star}, a^{\star}, b^{\star}\right.$ and $\left.\Delta E\right)$ in vegetable juice mixture after $24 \mathrm{~h}$ and $48 \mathrm{~h}$ of fermentation. There was an increase of lightness. This result disagreed with lactic-acid fermented mulberry juice [40] and with cashew apple juice fermented with Lactobacillus casei [26]. There was an increase biomass during the fermentation providing a turbidity of juice. However, the increase of lightness was the result of $\mathrm{pH}$ reduction in vegetable juice mixture containing carrot juice. According to the investigation of Chen, Peng [41], the lightness $\left(L^{\star}\right)$ of carrot juice increased after acidification. It has reported that blanching carrots with acid can increase the brightness and decrease the precipitation of carrot juice during processing, improve the color and turbidity of heated or canned juice [42].

The fermentation also resulted an increase in $\mathrm{a}^{\star}$ and $\mathrm{b}^{\star}$, indicating the redness and yellowness of vegetable juice mixture increased. Carotenoids are the main pigments responsible for the color of carrot roots and juices. Trans carotenoid isomers are predominant in nature and under extreme $\mathrm{pH}$ values (acid and alkali), can be transformed to cis carotenoid isomers and cause color change in carrot juice [41]. A similar trend has also been reported by Pereira, Maciel [26]. The $\Delta \mathrm{E}$ values of fermented vegetable juice mixture with $L$. acidophilus and $L$. plantarum fell within the slightly noticeable range $0.5<\Delta \mathrm{E}<2$ [43]. The juices inoculated with $L$. plantarum had a greater $\Delta \mathrm{E}$ value (Table 4 ) compared to the juice inoculated with $L$. acidophilus.

\subsection{Storage of the Probiotic Vegetable Juice Mixture}

\subsubsection{Effect of Cold Storage on Cell Viability}

The juice mixtures after $24 \mathrm{~h}$ fermentation were stored at $4^{\circ} \mathrm{C}$ for 28 days showed the different cell viability between two strains (Table 5). L. plantarum was highly capable of surviving in the fermented juice mixture until the end of storage, the viable cell count remained at $7.95 \log \mathrm{CFU} / \mathrm{mL}$ after 28 days of cold 
Table 4. Colorimetric properties of vegetable juice mixture during fermentation.

\begin{tabular}{|c|c|c|c|c|c|}
\hline Lactobacillus strain & Time (h) & $\mathrm{L}^{*}$ & $a^{*}$ & $b^{*}$ & $\Delta \mathrm{E}$ \\
\hline \multirow[t]{3}{*}{ L. plantarum } & 0 & $44.57 \pm 0.06^{\mathrm{c}}$ & $24.38 \pm 0.03^{c}$ & $35.72 \pm 0.07^{\mathrm{b}}$ & - \\
\hline & 24 & $45.75 \pm 0.07^{\mathrm{b}}$ & $24.77 \pm 0.10^{\mathrm{b}}$ & $35.94 \pm 0.04^{\mathrm{a}}$ & $1.26 \pm 0.07$ \\
\hline & 48 & $46.22 \pm 0.07^{\mathrm{a}}$ & $25.15 \pm 0.05^{\mathrm{a}}$ & $35.99 \pm 0.03^{\mathrm{a}}$ & $1.84 \pm 0.04$ \\
\hline \multirow[t]{3}{*}{ L. acidophilus } & 0 & $43.52 \pm 0.09^{b}$ & $24.04 \pm 0.09^{c}$ & $33.54 \pm 0.09^{\mathrm{b}}$ & - \\
\hline & 24 & $43.67 \pm 0.14^{\mathrm{ab}}$ & $24.56 \pm 0.08^{\mathrm{b}}$ & $33.72 \pm 0.08^{\mathrm{a}}$ & $0.57 \pm 0.04$ \\
\hline & 48 & $43.92 \pm 0.19^{\mathrm{a}}$ & $24.87 \pm 0.09^{\mathrm{a}}$ & $33.88 \pm 0.09^{\mathrm{a}}$ & $0.98 \pm 0.14$ \\
\hline
\end{tabular}

Data expressed as means \pm standard deviation $(n=3)$. Values in the same column followed by different superscript letters indicate statistically significant differences at $\mathrm{p}<0.05$. The values within column that do not have a common superscript are also significant different $(p<0.05)$. Unfermented vegetable juice mixture at $0 \mathrm{~h}$ is used as the control.

Table 5. Effect of cold storage on the viability of lactobacillus bacteria in fermented vegetable juice mixture.

\begin{tabular}{ccc}
\hline \multirow{2}{*}{ Time (days) } & \multicolumn{2}{c}{ Log CFU/mL } \\
\cline { 2 - 3 } & L.plantarum & L.acidophilus \\
\hline 1 & $8.88 \pm 0.06^{\mathrm{a}}$ & $7.57 \pm 0.01^{\mathrm{a}}$ \\
7 & $8.75 \pm 0.04^{\mathrm{b}}$ & $6.99 \pm 0.04^{\mathrm{b}}$ \\
14 & $8.56 \pm 0.05^{\mathrm{c}}$ & $6.31 \pm 0.09^{\mathrm{c}}$ \\
21 & $8.27 \pm 0.07^{\mathrm{d}}$ & $5.47 \pm 0.07^{\mathrm{d}}$ \\
28 & $7.95 \pm 0.08^{\mathrm{e}}$ & $4.57 \pm 0.07^{\mathrm{e}}$ \\
\hline
\end{tabular}

Data expressed as means \pm standard deviation $(n=3)$. Values in the same column followed by different superscript letters indicate statistically significant differences at $\mathrm{p}<0.05$.

storage, which is considered a great value for fermented products containing probiotics. In contrast, viable cell count of $L$. acidophilus decreased significantly during cold storage and remained at only $4.57 \log \mathrm{CFU} / \mathrm{mL}$ after 28 days. Pasteurization for the long period $\left(80^{\circ} \mathrm{C}, 15 \mathrm{~min}\right)$ could cause nutritional loss in the material which might have contributed to L. acidophilus viability loss. L. plantarum demonstrates a stronger viability than other Lactobacillus strains during cold storage time in fruit and vegetable juices [37] [44]. Generally, the cell viability depends on many factors as the strain used, interaction between species present, culture condition, oxygen content, final acidity of the product, and the concentration of lactic acid and acetic acid [15] [45] [46]. The presence of inulin and FOSs in fermentation medium probably had a positive impact on viability maintenance and improvement of probiotics during cold storage [47] [48]. In this present study, the product containing a combination of prebiotics and probiotics are known as synbiotics. This advantage would improve the survival of bacteria passing the upper part of gastrointestinal tract, improving their effects in the large bowel, and is able to enhance the growth of most positive gut bacteria [49]. 


\subsubsection{Effect of Cold Storage on Total Carotenoid Content and Color of Fermented Vegetable Juice Mixture}

After 28 days of cold storage, fermented vegetable juice mixtures with L. plantarum and L. acidophilus presented a loss about $23 \%$ and $16 \%$ of their initial total carotenoid content, respectively (Figure 1). The degradation level of carotenoids in juices inoculated with $L$. acidophilus was lower it could be because L. acidophilus viability decreased significantly during cold storage periods.

The results of color component $\left(\mathrm{L}^{*}, \mathrm{a}^{*}, \mathrm{~b}^{*}\right.$ and $\left.\Delta \mathrm{E}\right)$ in the fermented vegetable juice mixture during storage $\left(4^{\circ} \mathrm{C}, 28\right.$ days) were shown Figure 2 . The lightness increased during storage. A decrease in the color components $\mathrm{a}^{*}$ and $\mathrm{b}^{*}$ were also observed during storage (Figure 2). This implies that the cold storage resulted in a gradual weakening of color. Degradation of total carotenoid content and decrease of color components $\mathrm{a}^{*}$ and $\mathrm{b}^{*}$ could be related to each other and decrease of one affecting the other (Figure 1 and Figure 2). The total color difference $\Delta \mathrm{E}$ of fermented vegetable juice mixture increased during the storage. This increase was mainly due to change of all color parameters. Considering a $\Delta \mathrm{E}$ of 2 represents a noticeable color difference [43], the value reached at 14 th day $(\Delta \mathrm{E}=$ $2.58 \pm 0.25)$ of storage and increased until end storage $(\Delta \mathrm{E}=4.72 \pm 0.29)$ for fermented vegetable juice mixture with $L$. plantarum. While the vegetable juice mixture fermented with $L$. acidophilus reached $(\Delta \mathrm{E}=2.00 \pm 0.14)$ at the end of storage time.

\subsection{Sensory Evaluation}

The sensory assessment of vegetable mixture juices was conducted on 14th day of storage because all formulations (except CON) need to have culture counts high enough to be considered probiotic foods ( $>6 \log \mathrm{CFU} / \mathrm{mL}$ ) (Table 5). The acceptability of vegetable juice mixture is shown in Figure 3. The judges indicated that they liked the color and texture of juices in all formulations. Supplementation

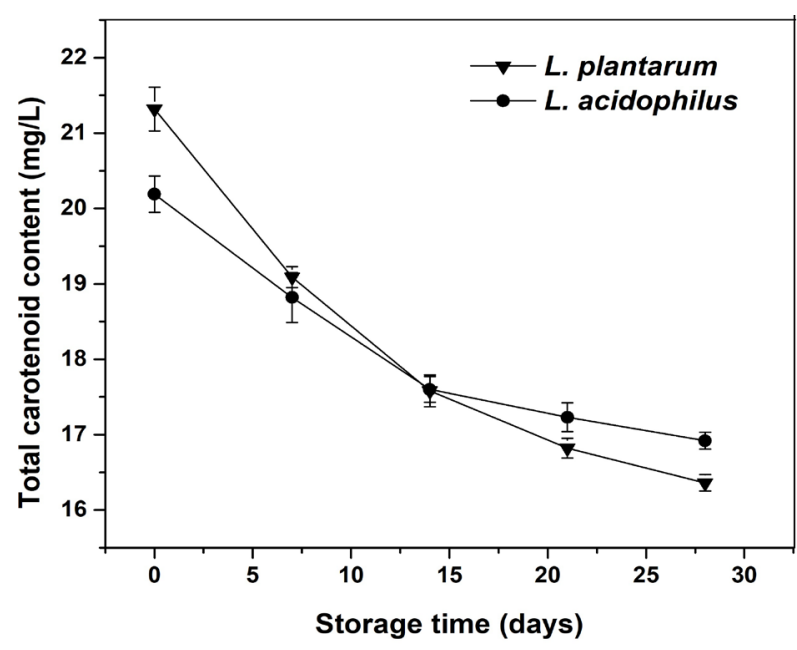

Figure 1. Total carotenoid content $(\mathrm{mg} / \mathrm{L})$ of fermented vegetable juice mixture, inoculated with Lactobacillus plantarum and Lactobacillus acidophilus during storage for 28 days. 




(a)

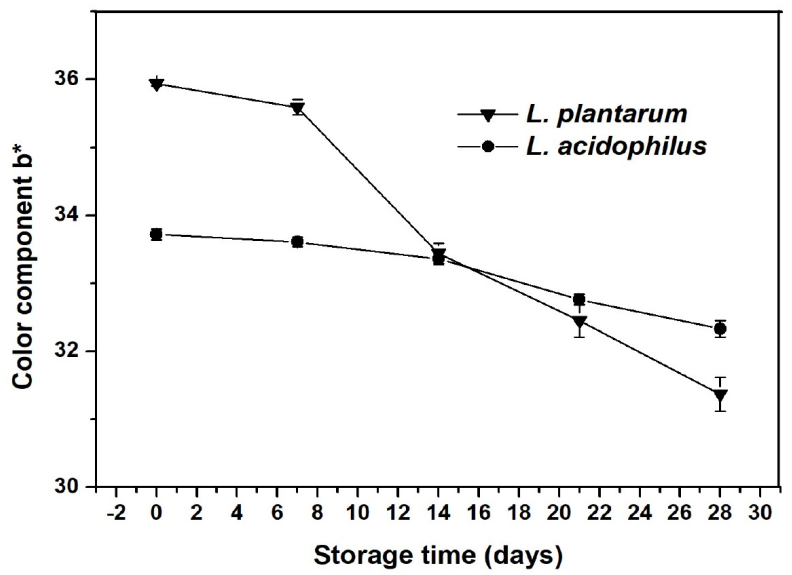

(c)

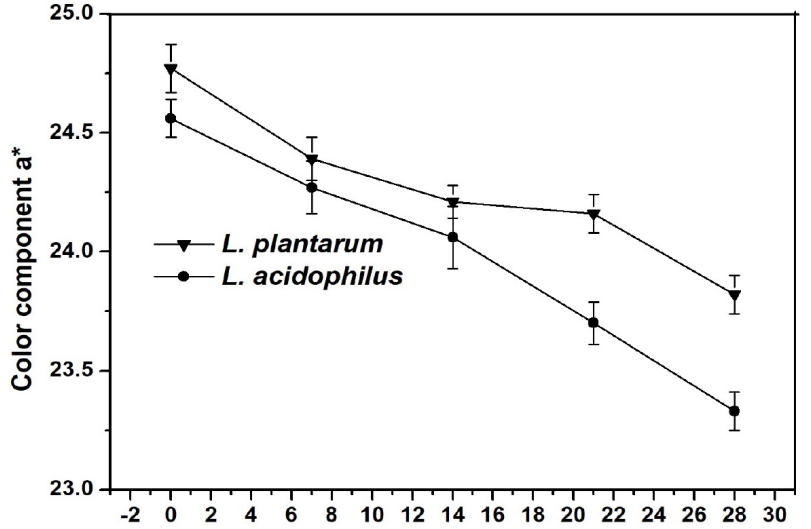

(b)

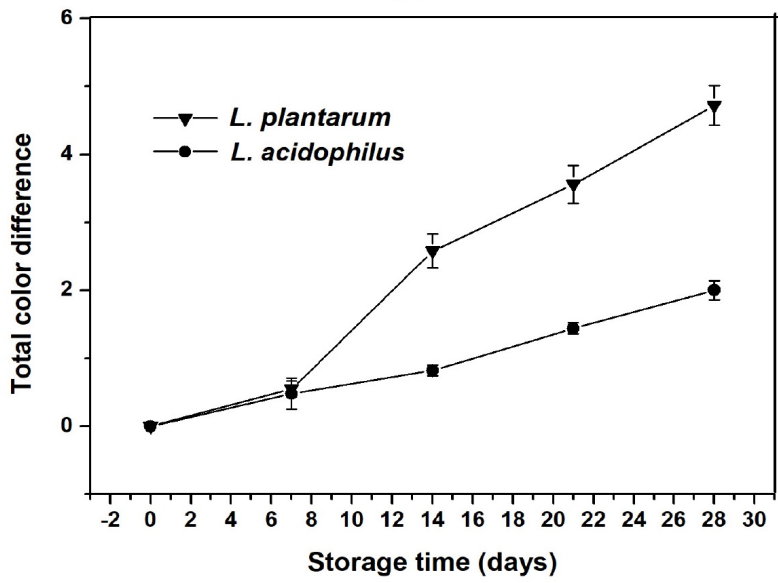

(d)

Figure 2. Color component $\mathrm{L}^{\star}(\mathrm{a}), \mathrm{a}^{\star}(\mathrm{b}), \mathrm{b}^{\star}(\mathrm{c})$, and total color difference $\Delta \mathrm{E}$ (d) of fermented vegetable juice mixture, inoculated with Lactobacillus plantarum and Lactobacillus acidophilus during store for 28 days.



Figure 3. Acceptability of vegetable juice mixtures. Mean score $(n=21)$, The error bars represent the standard deviation. Hedonic values (color, odor, taste, texture and overall acceptance) are as follows: 1 = dislike extremely; 9 = like extremely. Formations: $\operatorname{CON}(\square)$, PFJ ( $\square$ ), AFJ ( $\square$ ), MASK-PFJ ( $\square)$, MASK-AFJ ( $\square$ ), SUC-PFJ ( $\square$ ), SUC-AFJ ( $/ /$ ) ). 
with sucrose and multi fruit juice (mainly tropical fruit juice) had no effect ( $\mathrm{p}>$ 0.05 ) on acceptability of color and texture. The highest acceptability was the CON formulation. The formulations without any supplements got low acceptability (odor, taste, overall acceptance). This is likely because the metabolism of the cultures results changes to the components in the juices that negatively contribute to the aroma and flavor of the final products. Probiotification of juices from fruits and vegetables were characterized as "medicinal", "acid", "bitter", "astringent", "salty" or "dairy". Fermented juices with L. plantarum had a stronger sour taste (Table 2) compared to fermented juices with L. acidophilus (Table 3), resulting in the PFJ formulation to earn the lowest acceptability. There was a significant increase $(\mathrm{p}<0.05)$ of acceptability (taste, overall acceptance).

In vegetable juice mixtures fermented with $L$. plantarum by adding the multi fruit juice (MASK-PFJ) or sucrose (SUC-PFJ) while the vegetable juice mixtures fermented with $L$. acidophilus by only adding sucrose (SUC-AFJ). The results indicated that the preference might be related to sweetness and the addition of pleasant aroma and volatile compounds is able to mask the presence of probiotics. However, the commercial juice was used in adding isn't a good choice to mask unpleasant flavor and change considerably sensory attributes of probiotic juices. A set of tests for mixing the vegetable juice mixture with a wide variety of commercial vegetable juice or fruit juice should be done to find the best option in improving effectively sensory quality. Herein, our study didn't reveal any information about the juices they evaluated which has a significant impact on consumer liking. Exposure and health information have positive effects on the overall liking of juices containing probiotic cultures [32] [50].

\section{Conclusion}

This research demonstrated both Lactobacillus strains were capable of having biochemical activities in vegetable juice mixture without any nutrient supplementation. Change in levels of physicochemical and microbiological characteristics in vegetable juice mixture during fermentation and cold storage depended on the strain used. As sensory analysis, acceptance of the probiotic vegetable juice mixtures was in range of 5 to 8 on a 9-point hedonic scale, which differed between the attribute evaluated and the strain used. Moreover, the sensory quality was improved positively by sucrose addition or adding multi fruit juice $(10 \%$ $\mathrm{v} / \mathrm{v}$, mainly tropical fruit juices). Based on the present findings, L. plantarum could be used as a culture for production of probiotic drink from vegetable juice mixture with high nutrient values and health benefits. Optimizing fermentation, improving survival of probiotics during cold storage, as well as enhancement of sensory traits for this vegetable juice mixture require further studies.

\section{Acknowledgements}

This research was supported by the financial support of the Six-Talent Peaks 
Project in Jiangsu Province and Qinglan Project, which has enabled us to carry out this study.

\section{Conflicts of Interest}

Authors declare that they have not any conflicts of interest.

\section{References}

[1] FAO/WHO (2002) Guidelines for the Evaluation of Probiotics in Food. Report of a Joint FAO/WHO Working Group on Drafting Guidelines for the Evaluation of Probiotics in Food, Ontario, Canada, 30 April-1 May 2002.

[2] Khezri, S., Dehghan, P., Mahmoudi, R. and Jafarlou, M. (2016) Fig Juice Fermented with Lactic Acid Bacteria as a Nutraceutical Product. Pharmaceutical Sciences, 22, 260-266. https://doi.org/10.15171/PS.2016.40

[3] Dipjyoti, C., Sourangshu, C. and Mohanasrinivasan, V. (2015) Fermentation of Psidiumguajava Juice by Using Probiotic Lactic acid Bacteria Lactobacillus plantarum. Journal of Nutrition and Food Sciences, 5, 398.

[4] Rivera-Espinoza, Y. and Gallardo-Navarro, Y. (2010) Non-Dairy Probiotic Products. Food Microbiology, 27, 1-11. https://doi.org/10.1016/j.fm.2008.06.008

[5] Costa, M.G.M., Fonteles, T.V., De Jesus, A.L.T. and Rodrigues, S. (2013) Sonicated Pineapple Juice as Substrate for $L$. casei Cultivation for Probiotic Beverage Development: Process Optimisation and Product Stability. Food Chemistry, 139, 261-266. https://doi.org/10.1016/j.foodchem.2013.01.059

[6] Kim, D.C., Chae, H.J. and In, M.J. (2010) Fermentation Characteristics of Korean pear (Pyrus pyrifolia Nakai) Puree by the Leuconostoc mesenteroides 51-3 Strain Isolated from Kimchi. African Journal of Biotechnology, 9, 5735-5738.

[7] Silva, S.B. and Ferrari, J. (2016) Development of Probiotic Grape Juice and Lactobacillus paracasei Viability under Cold Storage. X CIGR Section IV International Technical Symposium, XXV Congresso Brasileiro de Ciência e Tecnologia de Alimentos.

[8] Mousavi, Z.E., Mousavi, S.M., Razavi, S.H., Emam-Djomeh, Z. and Kiani, H. (2010) Fermentation of Pomegranate Juice by Probiotic Lactic Acid Bacteria. World Journal of Microbiology and Biotechnology, 27, 123-128. https://doi.org/10.1007/s11274-010-0436-1

[9] Wang, C.Y., Ng, C.C., Su, H., Tzeng, W.S. and Shyu, Y.T. (2009) Probiotic Potential of Noni Juice Fermented with Lactic Acid Bacteria and Bifidobacteria. International Journal of Food Sciences and Nutrition, 60, 98-106. https://doi.org/10.1080/09637480902755095

[10] Shisheh, S., Hashemiravan, M. and Jaktaji, R.P. (2014) Production of Probiotic Mixture of Barberry and Black Cherry Juice by Lactic Acid Bacteria. Bulletin of Environment, Pharmacology and Life Sciences, 3, 53-61.

[11] Tamminen, M., Salminen, S. and Ouwehand, A.C. (2013) Fermentation of Carrot Juice by Probiotics: Viability and Preservation of Adhesion. International Journal of Biotechnology for Wellness Industries, 2, 10-15.

[12] Rakin, M., Vukasinovic, M., Siler-Marinkovi, S. and Maksimovic, M. (2007) Contribution of Lactic Acid Fermentation to Improved Nutritive Quality Vegetable Juices Enriched with Brewer's Yeast Autolysate. Food Chemistry, 100, 599-602. https://doi.org/10.1016/j.foodchem.2005.09.077 
[13] Panda, S.H. and Ray, R.C. (2007) Lactic Acid Fermentation of Beta-Carotene Rich Sweet Potato (Ipomoea batatas L.) into Lacto-Juice. Plant Foods for Human Nutrition, 62, 65-70. https://doi.org/10.1007/s11130-007-0043-y

[14] Kim, N.J., Jang, H.L. and Yoon, K.Y. (2012) Potato Juice Fermented with Lactobacillus casei as a Probiotic Functional Beverage. Food Science and Biotechnology, 21, 1301-1307. https://doi.org/10.1007/s10068-012-0171-5

[15] Tripathi, M.K. and Giri, S.K. (2014) Probiotic Functional Foods: Survival of Probiotics during Processing and Storage. Journal of Functional Foods, 9, 225-241. https://doi.org/10.1016/j.jff.2014.04.030

[16] Noman, A.S.M., Hoque, M.A., Haque, M.M., Pervin, F. and Karim, M.R. (2007) Nutritional and Anti-Nutritional Components in Pachyrhizus erosus L. Tuber. Food Chemistry, 102, 1112-1118. https://doi.org/10.1016/j.foodchem.2006.06.055

[17] Ramos-De-La-Peña, A.M., Renard, C.M.G.C., Wicker, L. and Contreras-Esquivel, J.C. (2013) Advances and Perspectives of Pachyrhizus spp. in Food Science and Biotechnology. Trends in Food Science and Technology, 29, 44-54. https://doi.org/10.1016/j.tifs.2012.09.003

[18] Kumalasari, I.D., Nishi, K., Harmayani, E., Raharjo, S. and Sugahara, T. (2014) Immunomodulatory Activity of Bengkoang (Pachyrhizus erosus) Fiber Extract in Vitro and in Vivo. Cytotechnology, 66, 75-85. https://doi.org/10.1007/s10616-013-9539-5

[19] Pool-Zobel, B.L. (2007) Inulin-Type Fructans and Reduction in Colon Cancer Risk: Review of Experimental and Human Data. British Journal of Nutrition, 93, S73-S90. https://doi.org/10.1079/BJN20041349

[20] Park, C.J., Lee, H.A. and Han, J.S. (2015) Jicama (Pachyrhizus erosus) Extract Increases Insulin Sensitivity and Regulates Hepatic Glucose in C57BL/Ksj-db/db Mice. Journal of Clinical Biochemistry and Nutrition, 58, 56-63.

[21] Jiang, B., Liu, W., Peng, Q.W., He, X.M. and Xie, D.S. (2014) Characterization and Chromosomal Organization of Ty1-copia Retrotransposons in Wax Gourd. Gene, 551, 26-32. https://doi.org/10.1016/j.gene.2014.08.014

[22] Huang, G., Tan, J.T., Tan, X.C. and Peng, D.Q. (2011) Preparation of Polysaccharides from Wax Gourd. International Journal of Food Sciences and Nutrition, 62, 480-483. https://doi.org/10.3109/09637486.2010.550275

[23] Sun, X., Baldwin, E.A., Plotto, A., Manthey, J.A., Duan, Y.P. and Bai, J.H. (2017) Effects of Thermal Processing and Pulp Filtration on Physical, Chemical and Sensory Properties of Winter Melon Juice. Journal of the Science of Food and Agriculture, 97, 543-550. https://doi.org/10.1002/jsfa.7761

[24] Liu, Y., Huang, G. and Hu, J. (2018) Extraction, Characterisation and Antioxidant Activity of Polysaccharides from Chinese Watermelon. International Journal of Biological Macromolecules, 111, 1304-1307. https://doi.org/10.1016/j.ijbiomac.2018.01.088

[25] Kun, S., Rezessy-Szabó, J.M., Nguyen, Q.D. and Hoschke, Á. (2008) Changes of Microbial Population and Some Components in Carrot Juice during Fermentation with Selected Bifidobacterium Strains. Process Biochemistry, 43, 816-821. https://doi.org/10.1016/j.procbio.2008.03.008

[26] Pereira, A.L.F., Maciel, T.C. and Rodrigues, S. (2011) Probiotic Beverage from Cashew Apple Juice Fermented with Lactobacillus casei. Food Research International, 44, 1276-1283. https://doi.org/10.1016/j.foodres.2010.11.035

[27] Sadler, G.D. and Murphy, A.P.H. (2010) pH and Titratable Acidity. In: Nielsen, S.S., 
Ed., Food Analysis, Springer, Boston, MA, 219-238.

[28] Dubois, M., Gilles, K.A., Hamilton, J.K., Rebers, P.A. and Smith, F. (1956) Colorimetric Method for Determination of Sugars and Related Substances. Analytical Chemistry, 26, 350-356.

[29] Adiamo, O.Q., Ghafoor, K., Al-Juhaimi, F., Ahmed, I.A.M. and Babiker, E.E. (2017) Effects of Thermosonication and Orange By-Products Extracts on Quality Attributes of Carrot (Daucus carota) Juice during Storage. International Journal of Food Science and Technology, 52, 2115-2125. https://doi.org/10.1111/ijfs.13490

[30] Vinderola, C.G. and Reinheimer, J.A. (2000) Enumeration of Lactobacillus casei in the Presence of L. acidophilus, Bifidobacteria and Lactic Starter Bacteria in Fermented Dairy Products. International Dairy Journal, 10, 271-275. https://doi.org/10.1016/S0958-6946(00)00045-5

[31] Okoro, C.I., Ihenetu F.C., Ogwunga, C.C. and Dunga, K.E. (2017) Study on the Antibacterial Properties of Probiotic Bacteria Isolated from Human Breast Milk. Journal of Scientific Research and Studies, 4, 264-268.

[32] Luckow, T., Sheehan, V., Fitzgerald, G. and Delahunty, C. (2006) Exposure, Health Information and Flavour-Masking Strategies for Improving the Sensory Quality of Probiotic Juice. Appetite, 47, 315-323. https://doi.org/10.1016/j.appet.2006.04.006

[33] Aryana, K., Plauche, S., Rao, R.M., McGrew, P. and Shah, N.P. (2007) Fat-Free Plain Yogurt Manufactured with Inulins of Various Chain Lengths and Lactobacillus acidophilus. Journal of Food Science, 72, M79-M84. https://doi.org/10.1111/j.1750-3841.2007.00302.x

[34] Shah, N. (2007) Functional Cultures and Health Benefits. International Dairy Journal, 17, 1262-1277. https://doi.org/10.1016/j.idairyj.2007.01.014

[35] Pakbin, B., Razavi, S.H., Mahmoudi, R. and Gajarbeygi, P. (2014) Producing Probiotic Peach Juice. Biotechnology and Health Sciences, 1, Article No. e24683.

[36] Yoon, K.Y., Woodams, E.E. and Hang, Y.D. (2004) Probiotication of Tomato Juice by Lactic Acid Bacteria. Journal of Microbiology, 42, 315-318.

[37] Yoon, K.Y., Woodams, E.E. and Hang, Y.D. (2006) Production of Probiotic Cabbage Juice by Lactic Acid Bacteria. Bioresource Technology, 97, 1427-1430. https://doi.org/10.1016/j.biortech.2005.06.018

[38] Sharma, V. and Mishra, H.N. (2013) Fermentation of Vegetable Juice Mixture by Probiotic Lactic Acid Bacteria. Nutrafoods, 12, 17-22. https://doi.org/10.1007/s13749-012-0050-y

[39] Liu, Y., et al. (2018) Beneficial Effects of Tomato Juice Fermented by Lactobacillus plantarum and Lactobacillus casei: Antioxidation, Antimicrobial Effect, and Volatile Profiles. Molecules, 23, 2366. https://doi.org/10.3390/molecules23092366

[40] Kwaw, E., et al. (2018) Effect of Lactobacillus Strains on Phenolic Profile, Color Attributes and Antioxidant Activities of Lactic-Acid-Fermented Mulberry Juice. Food Chemistry, 250, 148-154. https://doi.org/10.1016/j.foodchem.2018.01.009

[41] Chen, B.H., Peng, H.Y. and Chen, H.E. (1995) Changes of Carotenoids, Color, and Vitamin A Contents during Processing of Carrot Juice. Journal of Agricultural and Food Chemistry, 43, 1912-1918. https://doi.org/10.1021/jf00055a029

[42] Andrés-Bello, A., Barreto-Palacios, V., García-Segovia, P., Mir-Bel, J. and Martínez-Monzó, J. (2013) Effect of pH on Color and Texture of Food Products. Food Engineering Reviews, 5, 158-170. https://doi.org/10.1007/s12393-013-9067-2

[43] Lee, H.S. and Coates, G.A. (2003) Effect of Thermal Pasteurization on Valencia Orange Juice Color and Pigments. LWT_Food Science and Technology, 36, 153-156. 
https://doi.org/10.1016/S0023-6438(02)00087-7

[44] Reddy, L.V., Min, J.H. and Wee, Y.J. (2015) Production of Probiotic Mango Juice by Fermentation of Lactic Acid Bacteria. Microbiology and Biotechnology Letters, 43, 120-125. https://doi.org/10.4014/mbl.1504.04007

[45] Dianawati, D., Mishra, V. and Shah, N. (2016) Survival of Microencapsulated Probiotic Bacteria after Processing and during Storage: A Review. Critical Reviews in Food Science and Nutrition, 56, 1685-1716. https://doi.org/10.1080/10408398.2013.798779

[46] Reale, A., et al. (2015) Tolerance of Lactobacillus casei, Lactobacillus paracasei and Lactobacillus rhamnosus Strains to Stress factors Encountered in Food Processing and in the Gastro-Intestinal Tract. LWT-Food Science and Technology, 60, 721-728. https://doi.org/10.1016/j.lwt.2014.10.022

[47] Nazzaro, F., Fratianni, F., Sada, A. and Orlando, P. (2008) Synbiotic Potential of Carrot Juice Supplemented with Lactobacillus spp. and Inulin or Fructooligosaccharides. Journal of the Science of Food and Agriculture, 88, 2271-2276. https://doi.org/10.1002/jsfa.3343

[48] Paseephol, T. and Sherkat, F. (2009) Probiotic Stability of Yoghurts Containing Jerusalem Artichoke Inulins during Refrigerated Storage. Journal of Functional Foods, 1, 311-318. https://doi.org/10.1016/j.jff.2009.07.001

[49] Roberfroid, M.B. (1999) Concepts in Functional Foods: The Case of Inulin and Oligofructose. The Journal of Nutrition, 129, 1398S-1401S. https://doi.org/10.1093/jn/129.7.1398S

[50] Pereira, A.L.F., et al. (2017) Impact of Fermentation Conditions on the Quality and Sensory Properties of a Probiotic cupuassu (Theobroma grandiflorum) Beverage. Food Research International, 100, 603-611. https://doi.org/10.1016/j.foodres.2017.07.055 